\title{
O Serviço Social e a área de gestão de pessoas: mediações sintonizadas com a Política Nacional de Humanização no Hospital Giselda Trigueiro*
}

\section{The Social Services and the area of people management: mediations in tune with the National Policy of Humanization of Hospital Giselda Trigueiro}

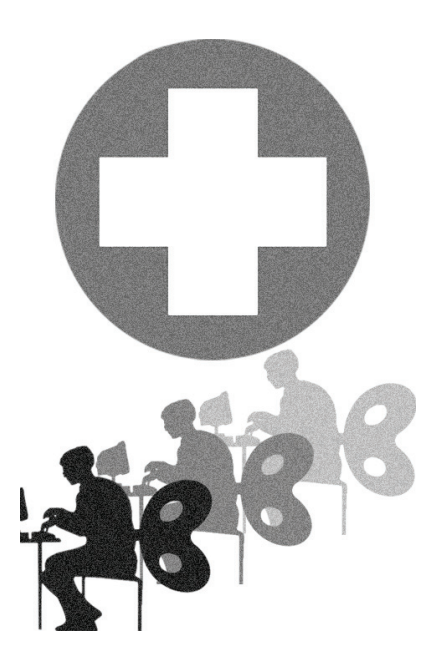

Maria Figuerêdo de Araújo Regis **

\begin{abstract}
Resumo: Este artigo socializa possibilidades concretas de atuação do Serviço Social em processos de trabalho na área de gestão de pessoas em saúde pública, a partir de experiência no Hospital Giselda Trigueiro, Natal, Rio Grande do Norte. Revela a importância da inserção de assistentes sociais nesses processos e, particularmente, da opção pelo projeto ético-político profissional para o desenvolvimento e ampliação de atividades coerentes com a Política Nacional de Humanização, que por sua vez, busca a efetivação dos princípios do Sistema Único de Saúde, tanto no âmbito da atenção como da gestão em Saúde.
\end{abstract}

Palavras-chave: Serviço Social. Gestão de pessoas. Projeto Ético-Político Profissional. Política Nacional de Humanização. Sistema Único de Saúde.

\begin{abstract}
This article socializes concrete possibilities for action in cases of Social services in the area of people management in public health, from experience in Hospital Giselda Trigueiro, Natal, Rio Grande do Norte. Reveals the importance of social workers inclusion of these processes, and particularly, the

* Texto fruto da inserção em processos de trabalho, a partir de 2009, como assistente social, assessora do Núcleo de Recursos Humanos e coordenadora do colegiado gestor da Unidade de Gestão de Pessoas do Hospital Giselda Trigueiro, Natal/RN, Brasil.

** Assistente social e mestra em Serviço Social pela UFRN — Natal/RN, Brasil. Professora do Programa de Pós-Graduação Lato Sensu da Facex, Natal (RN), assessora de Recursos Humanos e coordenadora do colegiado da Unidade de Gestão de Pessoas do Hospital Giselda Trigueiro, Natal (RN). E-mail: marialotus@bol.com.br.
\end{abstract}


choice of project ethical political professional development and expansion of activities consistent with the National Policy of Humanization, which in turn, seeks effectuation of the principles of the Unique Health System, both under the care and management in Health.

Keywords: Social Work. People management. Project Ethical-Political Professional. National Policy of Humanization. Unique Health System.

\section{Introdução}

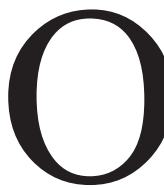

s anos 1990 no Brasil despontaram com desafios históricos, que se referem, entre outros, à concretização de avanços teóricos/legais expressos na Constituição de 1988. Um exemplo de tais desafios é a sistematização de uma política de saúde tratada como um direito social a ser garantido pelo Estado de forma universal, igualitária e gratuita a todos os brasileiros, que inclui a criação e a sustentação do Sistema Único de Saúde (SUS).

Como mostra Menicucci (2006, p. 59), esses avanços têm facilitado a definição de uma engenharia institucional capaz, entre outras coisas, de

estabelecer arranjos federativos que definam de forma eficaz as relações intergovernamentais e resolvam os problemas da coordenação, fundamentais no contexto de uma política descentralizada e de grandes heterogeneidades regionais e municipais, tanto em relação às capacidades financeiras, técnicas e organizacionais, quanto no perfil sanitário e nas características políticas.

Mas, apesar de ganhos no setor de saúde, tanto no trato à cobertura quanto à qualidade da atenção e gestão, são visíveis as ambiguidades e dificuldades da assistência na área, em grande parte herdadas dos anos 1960, que contribuiram para a formatação de um "sistema dual", ou seja, uma assistência com dupla institucionalidade, tanto quanto ao acesso, financiamento e produção de serviços de saúde, como de atuação governamental: uma forma pública - estatal na qual a ação de governo busca garantir o direito constitucional à saúde, e outra privada que objetiva regular o mercado, buscando garantir a concorrência, e assim desenvolver esse mercado, bem como os direitos do consumidor que adquire planos privados de saúde.

Trata-se de questões que vão além da órbita governamental e do sistema público, e como afirma tal autora, "tem sido negligenciadas, tanto nas análises com objetivos mais técnicos e práticos, quanto nas pesquisas de caráter mais acadêmico" (Menicucci, 2006, p. 59), ao contrário do que ocorre quando se trata de estudos 
sobre o funcionamento interno do SUS, principalmente em termos de financiamento, capacidade de gestão e definição de fluxos assistenciais.

Sem desconsiderarmos a importância de estudarmos tais questões, neste artigo, focaremos aspectos internos do SUS, quando nos voltaremos para a socialização de modos de produzir a saúde, a partir de processos de trabalho na área de gestão de pessoas, nos quais se inserem diversos profissionais, entre eles assistentes sociais; modos esses que não estão desvinculados das questões externas ao Sistema e influem diretamente no desenvolvimento de uma atenção e gestão de qualidade no âmbito da saúde pública.

Nesse sentido, faremos no primeiro momento algumas reflexões sobre a Política Nacional de Humanização - PNH e a sua importância para um SUS de qualidade. Em seguida, trataremos do Serviço Social inserido na área de gestão de pessoas, com enfoque na Unidade de Gestão de Pessoas - UGP do Hospital Giselda Trigueiro - HGT, quando socializaremos algumas mediações importantes para o desenvolvimento da PNH. Busca ainda incentivar a capacitação de estudantes e profissionais nessa área em expansão, inclusive, para assistentes sociais.

\section{A PNH: movimento em prol de mudanças nos modelos de atenção e gestão da saúde pública}

Estratégias no campo de pesquisas e políticas, dentre elas a PNH, criada em 2003 pelo Ministério da Saúde, ${ }^{1}$ busca superar aspectos como

O despreparo dos profissionais e demais trabalhadores para lidar com a dimensão subjetiva que toda a prática de saúde pressupõe. Ligado a esse aspecto, um outro que se destaca é a presença de modelos de gestão centralizados e verticais, desapropriando o trabalhador de seu próprio processo de trabalho. (PNH, 2009, p. 8)

A humanização passa a ser tratada como política a ser aplicada de forma transversal na rede SUS (o que inclui os diversos serviços do Sistema), devendo

1. A PNH é fruto da sistematização de ideias e práticas de diversos profissionais no Brasil adeptos ao Projeto de Reforma Sanitária brasileiro e, portanto, comprometidos com a sustentabilidade de uma política de saúde pública universal de qualidade. Para um maior aprofundamento sobre esse Projeto, ver Paim (2008), Bravo (1996) e Teixeira (1989). 
ser entendida como a "valorização dos diferentes sujeitos implicados no processo de produção de saúde: usuários, trabalhadores e gestores" (PNH, 2009, p. 8).

Os princípios dessa política tocam no âmago de problemas reais no SUS que são: compartimentalização de saberes, problemas no fluxo da comunicação entre os trabalhadores, separação entre a atenção e gestão dos serviços de saúde e a falta de autonomia dos sujeitos, a ponto de não se sentirem corresponsáveis no processo de cuidar e gerenciar os serviços.

Nesse sentido, a PNH tem três princípios intrínsecos, que são a transversalidade, o que implica o aumento e mudanças na relação e comunicação entre todos que estão envolvidos na produção de saúde e uma "desestabilização das fronteiras dos saberes, dos territórios de poder e dos modos instituídos na constituição das relações de trabalho" (PNH, 2009, p. 23); a indissociabilidade entre atenção e gestão, inviável se não houver mudanças integradas entre modelos de gestão e de cuidar nos diferentes processos de trabalho; e o protagonismo, corresponsabilidade e autonomia dos sujeitos e dos coletivos, o que implica a necessidade de que no cotidiano dos diferentes espaços do SUS haja uma busca pela afirmação da autonomia dos diferentes sujeitos envolvidos e o envolvimento dos mesmos como corresponsáveis.

Implementar tais princípios, bem como diretrizes e dispositivos presentes na PNH, não se apresenta como uma ação simples, ao considerarmos os problemas enfrentados pelo paradigma sanitário que origina o SUS, visto que esse sistema "rema contra a maré, já que vem sendo implantado em um contexto cultural e político que dificulta a estruturação de políticas públicas" (Campos, 2006, p. 137). Trata-se da expansão de um paradigma liberal.

A formalização de tal sistema se dá num período (anos 1980-90) em que o discurso e a prática predominante é o neorreformismo liberal, hegemônico no mundo, e busca a focalização dos programas sociais; a responsabilização do atendimento à população ao setor privado ou a organizações não governamentais (ONGs); restrição do papel do Estado como regulador do mercado e prestador de alguns serviços considerados "estratégicos", por antes já serem da alçada da saúde pública. Portanto, contrário ao ideário do SUS.

Em síntese, o contexto histórico no qual foi construído e alimentado esse sistema de saúde tem provocado várias dificuldades por se tratar de uma reforma, no dizer de Campos (2006, p. 144) "incompleta e permeada pelo paradoxo de pretender implantar uma política universalista em um contexto de ajuste econômico muito estrito". 
Explicitam-se no cotidiano brasileiro problemas no campo do financiamento do SUS e problemas relativos ao modo de reorganização do que se formalizou modelo de atenção à saúde. Quanto a essa reorganização, segundo Campos (2006, p. 144),

Em geral, os conceitos e métodos para reformular o paradigma tradicional da atenção à saúde no Brasil não foram transformados em leis, havendo, portanto, espaço para que os municípios expandam a cobertura segundo formas antigas. Nada obriga um município a incorporar preceitos da promoção à saúde, ou da clínica ampliada, ou do trabalho em equipe, ou mesmo a adoção de protocolos e programas de educação continuada, ou sistemas de avaliação, e, em várias localidades, o sistema ainda é hospitalocêntrico e centrado no atendimento médico de urgência.

Assim, são notórias as dificuldades no processo de reorganização da saúde pública, inclusive em se concretizar a $\mathrm{PNH}$, o que não elimina a importância da mesma para a efetivação de um SUS de qualidade.

A seguir, mostraremos algumas ações, as quais consideramos avanços, embora preliminares, bem como dificuldades e desafios em termos de mudanças no modo de atenção e gestão no SUS ao retratar a criação e o desenvolvimento da Unidade de Gestão de Pessoas (UGP) do Hospital Giselda Trigueiro (HGT), bem como a inserção de assistentes sociais em tais processos.

\section{0 Serviço Social e a UGP: mediações sintonizadas com a PNH}

A questão da atenção e gestão da saúde pública não deve ser vista desfocada do surgimento e expansão de uma reestruturação na forma de acumulação do capital a partir de meados dos anos 1990 no Brasil. Sobre tal reestruturação, Harvey (2000, p. 135) nos mostra que faz parte de um processo iniciado nos países de economia capitalista avançada entre 1965 e 1973 e explicitado pela "incapacidade do fordismo e do keynesianismo de conter as contradições inerentes ao capitalismo".

Passam a existir formas de "acumulação flexível" que incluem necessariamente novos processos de gestão. Sobre esses, Pimenta (1999) nos mostra que se revelam com base em quatro indicadores principais: a mudança do paradigma taylorista/fordista, a transformação social das empresas, a emergência de um novo "modelo" de trabalhador e a transformação do trabalho em termos de concepção e realização. 
Esses indicadores já identificados, inclusive, no Rio Grande do Norte por Araújo (2005), quando estudou o novo paradigma do Serviço Social da Indústria (Sesi) a partir de meados dos anos 1990, incluem a necessidade de implantação e reformulação no que diz respeito à gestão de recursos humanos, no sentido de investir em ações voltadas para os trabalhadores envolvidos na produção para que estes desenvolvam bem suas atividades.

Em outras palavras, "para mobilizar e utilizar plenamente as pessoas em suas atividades, as organizações estão mudando os seus conceitos e alterando as práticas gerenciais" (Chiavenato, 1999, p. 4). Se a preocupação até os anos 1990 era muito mais voltada para a estrutura organizacional, a partir deste ano, o que passa a ser centro das atenções são os aspectos dinâmicos e, portanto "as pessoas passam a ser a principal base da nova organização" (Idem).

Essa nova perspectiva tende a provocar uma mudança de nomenclatura: o que antes era chamado de "Administração de Recursos Humanos" (ARH) passa a ser chamado de "Gestão de Pessoas". Atentemos para o fato de que não significa apenas uma mudança de nomenclatura, uma vez que a mudança para o termo "gestão de pessoas" surge predominantemente como uma estratégia dos proprietários dos bens de produção para conseguir maior engajamento dos trabalhadores, os quais detêm conhecimentos importantes para o maior enriquecimento das organizações.

A tendência é que as empresas deem ênfase ao seu potencial humano e à sua cultura para, em troca, solicitar maior engajamento de seu pessoal, tanto individual quanto coletivo, na qualidade do trabalho desenvolvido. Surge, então, a preocupação com a criação de Programas de Qualidade Total (PQTs), bem como o surgimento de Círculos de Controle de Qualidade (CCQs), enquanto estratégias apresentadas para a reestruturação produtiva no Brasil, principalmente a partir dos anos 1990.

Estamos diante de uma reorganização profunda de concepção e realização do trabalho, que fazem pulular nomenclaturas como gestão de pessoas, planejamento estratégico, gestão participativa, colaboradores, entre tantas outras, como competência, polivalência, flexibilidade e transferibilidade.

Ao trazermos para o foco deste trabalho o termo gestão de pessoas, podemos afirmar que a questão básica em chamar de gestão de RH ou de pessoas está no fato de

escolher entre tratar as pessoas como recursos organizacionais ou como parceiros da organização. [...] como recursos, eles precisam ser administrados, o que envolve 
planejamento, organização, direção e controle de suas atividades, já que são considerados sujeitos passivos da ação organizacional [...]. Mas as pessoas podem ser visualizadas como parceiros das organizações. Como tais, elas são fornecedoras de conhecimentos, habilidades, capacidades e, sobretudo, o mais importante aporte para as organizações - a inteligência, que proporciona decisões racionais e imprime o significado e rumo aos objetivos globais. Desse modo, as pessoas constituem o capital intelectual da organização. (Chiavenato, 1999, p. 7)

A citação do autor tem uma carga ideológica, no sentido de imbuir nos trabalhadores uma ideia de parceria, colaboração para um mesmo empreendimento e de que, assim, todos saem ganhando no processo. Mas tal mudança de ótica não exclui as contradições entre capital/trabalho que tem se acentuado ao longo da história do capitalismo.

Ao comparamos essas mudanças paradigmáticas com a formatação ideológica da política de saúde no Brasil, consideramos que as mesmas perpassam todo o sistema de saúde, adquirindo rearranjos reforçadores da dualidade entre o público e o privado no que diz respeito à forma de utilização das ideias e de modelos de administração.

No caso específico do SUS e da PNH, há o uso de terminologias que já estão há mais tempo sendo adotadas nas organizações do âmbito privado capitalista (gestão de pessoas, gestão participativa, planejamento estratégico, entre outros). Mas há também um esforço real em reorientá-las no sentido de garantir uma sintonia com os princípios universalistas e autonomia dos sujeitos, o que não é fácil, pois ao mesmo tempo em que fortalece o SUS e o atualiza, põe-se contrário ao paradigma do capital, favorecedor da privatização dos serviços públicos e/ou do enxugamento dos recursos nesse âmbito.

É nesse contexto que foi criada a UGP do HGT, hospital de caráter público, que surgiu em 1943 em Natal, Rio Grande do Norte, referência no tratamento de doenças infecciosas, com aproximadamente 800 trabalhadores (estatutários e terceirizados), hoje com a missão de "promover atenção integral aos usuários com doenças infecciosas, garantindo qualidade, resolutividade e humanização na assistência, com ética e responsabilidade social, de acordo com os princípios do SUS" (Hospital Giselda Trigueiro, 2010, p. 4).

Pioneiro no estado, desde 2007 tem buscado mudar o modelo de atenção e gestão para seguir os princípios e dispositivos da PNH, o que inclui o foco na gestão participativa, a exemplo de alguns hospitais espalhados no Brasil, entre eles 
o Hospital Municipal Odilon Behrens, em Belo Horizonte. Inclui a reorganização do organograma institucional a partir do delineamento das unidades de produção (ou unidades funcionais) e seus respectivos colegiados gestores, com o objetivo de atingir da forma mais democrática possível a missão a qual se propõe.

Conforme Campos, apud Rates (2008, p. 51), essas unidades são espaços organizados conforme lógicas específicas de cada processo de trabalho que aglutinam "todos os profissionais envolvidos com um mesmo tipo de trabalho, com um determinado produto ou objetivo identificável". Podem originar-se por meio da fusão de antigos setores que nos moldes da gestão clássica estavam fragmentados, embora lidassem com objetos comuns e, ao serem criados, devem formar os seus respectivos colegiados gestores com o objetivo de discutir, avaliar, planejar e deliberar os seus processos de trabalho, além de democraticamente eleger um dos integrantes para coordenar tal unidade.

A UGP, criada em 2009, agrupa três setores que desenvolvem processos de trabalho afins: Setor de Pessoal, Setor de Saúde do Trabalhador e Núcleo de Recursos Humanos. Tal reordenamento ocasionou, por conseguinte, a criação de uma missão aglutinadora das finalidades desses três setores, bem como a reorganização física dos mesmos, de modo que dois desses passaram a ocupar uma mesma sala e o outro foi posicionado o mais próximo possível para facilitar a troca de informações e a agilidade para com o tratamento às demandas dos trabalhadores. ${ }^{2}$

Ocasionou também grandes desafios, entre eles o de desconstrução por parte de cada membro das equipes da ideia de que uns mandam (chefes) e a maioria só obedece; uns planejam (os chefes) e outros só executam; a construção e o fortalecimento da perspectiva interdisciplinar capaz de compreender que a saúde deve ser tratada em suas diversas dimensões e, por isso, os processos de trabalho precisam ser desenvolvidos de forma articulada com diferentes saberes em busca de maior poder de resolução e qualidade dos serviços e o consequente fortalecimento da cidadania de todos os envolvidos.

Nesse contexto, dois profissionais de Serviço Social foram solicitados pela direção geral do HGT para integrarem a equipe da UGP composta por diferentes

2. É importante destacar que o processo de legitimação da UGP é lento, visto que, como ainda a proposta do novo organograma não foi aprovada nas devidas instâncias e, portanto, reconhecida pela Secretaria de Saúde Pública do estado, continua para esta não existindo formalmente a UGP, mas sim três setores com três chefes. Mas entendemos que a partir da construção cotidiana de práticas ressignificadoras de novas nomenclaturas será possível a mudança no âmbito formal, até porque, pelos trabalhadores, nos parece ter sido aprovada. 
áreas: Terapia Ocupacional, Medicina, Técnico em Segurança no Trabalho, Biologia, Nutrição, Enfermagem, técnicos administrativos e estagiários, dentre eles de Serviço Social $^{3}$ e, juntamente a esses saberes, tem contribuído não só para a criação e desenvolvimento do colegiado gestor da unidade, mas também, para o alcance da missão, focada na melhoria da qualidade de vida no ambiente de trabalho, por meio do estímulo ao processo de educação permanente, relações interpessoais éticas e respeito ao SUS.

A presença desse profissional na UGP vem reforçar o que Iamamoto (2001, p. 130) fala sobre o crescimento do espaço ocupacional dos assistentes sociais na área de Recursos Humanos.

Esses têm sido chamados a atuar em programas de "qualidade de vida no trabalho", saúde do trabalhador, gestão de recursos humanos, prevenção de riscos sociais, círculos de qualidade, gerenciamento participativo, clima social, sindicalismo de empresa, reengenharia, administração de benefícios estruturados segundo padrões meritocráticos, elaboração e acompanhamento de orçamentos sociais, entre outros programas.

Mostra também a necessidade de o assistente social adquirir novas funções e competências entre elas, as voltadas para planejamento e gestão, "inscritos em equipes interdisciplinares que tensionam a identidade profissional" (Iamamoto, 2002, p. 37), visto que predominantemente na área de Recursos Humanos não é requerido, em sua maioria, atribuições privativas ${ }^{4}$ do assistente social, exceto nos casos que dizem respeito à matéria do Serviço Social, como, por exemplo, orientação de estágio curricular para estudantes de Serviço Social e realização de estudos sociais e pareceres técnicos para a elucidação de expressões da questão social, entre eles o absenteísmo.

Em sua maioria, são requeridas competências para intermediação e gerenciamento de conflitos, conhecimentos legais no âmbito trabalhista, capacidade de negociação, estratégias no trato de facilitar a educação permanente dos trabalhado-

3. Registramos o empenho das estagiárias do curso de Serviço Social da Facex, Elisângela da Silva Fonseca e Palloma Karla de Medeiros, que, em respostas às demandas apresentadas e/ou apreendidas pela UGP, construíram, em parceria com os gestores, um guia de serviços, enquanto instrumento contribuidor para a melhoria do fluxo de informação no HGT.

4. Sobre a diferença entre atribuições privativas e competências profissionais, ver Iamamoto (2002) e Lei n. 8.662/93. 
res e a valorização destes, o que inclui conhecimento sobre metodologias para a realização de capacitações, planejamento estratégico, avaliação de desempenho; enfim, como diz Iamamoto (2002, p. 38), "conhecimento e know-how na área de RH e relações de trabalho, entre outros". Trata-se da necessidade de uma escuta qualificada embasada em conhecimentos de disciplinas, principalmente de Administração, Psicologia, Pedagogia e Direito, o que não é sinônimo de o assistente social exercer a função de tais profissões, mas sim de que o mesmo encontre (ou facilite) as mediações possíveis para a resolução das questões apresentadas.

Quanto às mediações, são compreendidas como processos presentes na realidade, mas que nem sempre os profissionais conseguem apreendê-los, pois necessita de uma ação reflexiva, para a qual consideramos muito importantes duas ações: a pesquisa e a interdisciplinaridade. Como diz Freire (2003, p. 17), mediação é um processo tanto ontológico como reflexivo, e quanto ao último, se dá no momento em que se procura "captar processos anteriores e ocultos, com suas múltiplas mediações ontológicas, que estão por trás da aparência imediata".

Nesta linha de pensamento a UGP é um campo de mediações importante para a consolidação da PNH e do Projeto Ético Político Profissional, ${ }^{5}$ suscitadora de várias outras mediações que estão por trás das demandas espontâneas e dirigidas, implícitas e explícitas, possíveis de serem desvendadas por meio da ação reflexiva e interdisciplinar.

O Serviço Social nessa unidade tem contribuído com ações que se alinham nos quatro grandes eixos descritos nos Parâmetros para Atuação de Assistentes Sociais na Política de Saúde ${ }^{6}$ (CFESS, 2010), intermediando processos importantes para a produção de saúde de forma humanizada, a começar pela coordenação do colegiado gestor da unidade (já citada anteriormente), formado por $40 \%$ dos integrantes, com a responsabilidade de estar acionando um conjunto de saberes para que sejam cumpridas as atribuições básicas desse espaço que são:

5. Em relação ao projeto de profissão acima citado, faz-se necessário citar que, a exemplo da perspectiva de gestão participativa norteadora do HGT, é contrário à lógica privatista e desigual de nossa sociedade e se propõe a lutar pela liberdade, democracia, eliminação de todas as formas de preconceitos e compromisso com a qualidade dos serviços, entre outros princípios.

6. Os quatro grandes eixos são: atendimento direto aos usuários (no caso da UGP são todos os trabalhadores do hospital), mobilização, participação e controle social; investigação, planejamento e gestão, assessoria, qualificação e formação profissional. Para o aprofundamento sobre esses eixos, ver tais parâmetros (CFESS, 2010). 
Elaborar o projeto de ação; atuar no processo de trabalho da unidade; responsabilizar os envolvidos; acolher e encaminhar as demandas dos usuários; criar e avaliar os indicadores; sugerir e elaborar propostas; e criar estratégias para o envolvimento de todos os membros e equipes do serviço. (PNH, 2006, p.12)

Outras ações importantes são desenvolvidas, como: assessoria aos profissionais dos setores e/ou unidades de produção para tratar de questões referentes ao planejamento anual de atividades; subsídios técnicos e teóricos para requisição de recursos voltados para educação permanente dos profissionais; gestão de conflitos envolvendo profissionais de um mesmo setor ou entre setores diferenciados; deslocamento de profissionais entre setores do Hospital de acordo com a vontade do servidor, necessidade e possibilidade do serviço; acolhimento diário de novos servidores para tratar de procedimentos referentes ao ingresso nos processos de trabalho, bem como aos veteranos para informá-los sobre serviços disponíveis aos mesmos ou encaminhá-los para os serviços necessários; acompanhamento de questões relacionadas à inserção de estagiários no hospital (inclui o acompanhamento relativo ao dimensionamento dos estudantes de acordo com a capacidade setorial e de acompanhamento pelos preceptores); avaliação de desempenho; solicitação de resolutividade de casos de absenteísmo aos demais setores que compõe a UGP (Saúde do Trabalhador e Setor de Pessoal); ${ }^{7}$ encaminhamento de servidores para tratamento ao Núcleo de Assistência ao Servidor (Nasse) ou outro órgão; supervisão de estágio em Serviço Social, entre outras demandas relacionadas ao Núcleo de Recursos Humanos no âmbito administrativo/burocrático.

Destacamos dentre essas o empenho do Serviço Social para com a efetivação de uma função precípua do Núcleo, que é a estruturação e a coordenação de um programa de educação permanente para o HGT, que, apesar de várias dificuldades, tem se firmado desde o ano passado. ${ }^{8}$ Tal programa tem como objetivo facilitar $e$ coordenar o processo de educação permanente dos servidores do HGT, focado na

7. A inserção de um assistente social no setor de Saúde do Trabalhador/UGP em 2010 tem, entre outros objetivos, facilitar o encaminhamento de medidas relacionadas à promoção de saúde do trabalhador e questões do adoecimento no trabalho, causadoras de alto índice de absenteísmo.

8. A partir da qualificação de duas componentes da UGP no Curso de Especialização em Gestão do Trabalho e da Educação na Saúde, por meio do Programa de Qualificação e Estruturação da Gestão do Trabalho e da Educação no SUS (ProgeSUS), promovido pelo Núcleo de Estudos em Saúde Coletiva/Universidade Federal do Rio Grande do Norte (Nesc/UFRN), esperamos que o programa de educação permanente no HGT tenha mais sucesso em termos quantitativos e qualitativos. 
ética profissional, no respeito ao SUS e na melhoria das relações e processos de trabalho e está estruturado com base em quatro modalidades. A seguir apresentaremos algumas atividades que foram desenvolvidas no ano de 2010:

- Modalidade interna direta: compreende ações a serem efetivadas diretamente pelo Núcleo de RH/UGP a servidores do HGT, a partir da apreensão de necessidades de capacitação pela equipe ou por demandas dos trabalhadores. Ex.: curso de capacitação em recepção hospitalar; seminário de integração para os novos servidores, assessoria na construção de planejamento anual de atividades.

- Modalidade interna indireta: compreende ações desenvolvidas por diversas coordenações e/ou direções junto aos servidores no HGT, sendo essas assessoradas pelo Núcleo de RH/UGP. Exemplo: Curso com o setor de lavanderia e curso de gestão participativa, além de diversas rodas de conversas desenvolvidas nos colegiados gestores das unidades, visando a melhoria das relações e processos de trabalho.

- Modalidade externa: compreende ações externas ao HGT desenvolvidas por outras unidades ou programas, facilitadas pelo Núcleo de RH, setores/ UPs ou buscadas pelos próprios servidores, tendo em sua maioria o incentivo desse Núcleo (por meio da divulgação em quadros de avisos ou pessoalmente) e/ou coordenações de setores.

- Modalidade acadêmica: volta-se para o acompanhamento aos preceptores de todos os estagiários que se inserem no HGT, no sentido de melhor dimensionar os estudantes por setor, bem como ter ciência da estadia dos mesmos no hospital, a fim de contribuir na garantia de uma formação de profissionais com qualificação ética, técnica e política, de acordo com os princípios do SUS, o que inclui o respeito aos pacientes e trabalhadores das diversas equipes de trabalho nas quais se inserem tais estudantes.

Nesse sentido, as contribuições interdisciplinares nos fazem compreender a educação permanente na ótica de gestão participativa e do projeto ético-político profissional como um processo que vai além de simples capacitações técnicas para que os trabalhadores desenvolvam de forma mais eficiente os processos de trabalho. Mas sim como uma estratégia para mudanças institucionais, no sentido de melhorias substantivas no fluxo de comunicação, de pensar e de sentir de todos os envolvidos na gestão e na assistência dos serviços de saúde, que, embora apresente avanços 
em alguns aspectos, é prestada por trabalhadores com baixos salários, que convivem com a escassez de equipamentos e de colegas em determinadas áreas/cargos, entre outros indicadores que emperram o processo de educação permanente por provocarem desencanto, cansaço e descontentamento no cotidiano de trabalho.

\section{Considerações finais}

Diante do exposto, podemos perceber que a área de gestão de pessoas produz um movimento que transpõe as paredes da UGP e, certamente, do Serviço Social, envolvendo diversas especialidades e sendo transversal a todos os setores/UPs. Daí residir uma grande possibilidade para os profissionais de Serviço Social que atuam nesta área, por natureza interdisciplinar, que é garantir uma perspectiva generalista em prol do entendimento das mediações voltadas para a melhoria na produção de saúde e a elaboração de respostas profissionais.

É também uma área que traz desafios importantes, ocasionados, entre outras razões, pela não especificação, a priori, de atribuições privativas para o Serviço Social, mas sim por apresentar uma gama de demandas que precisam ser traduzidas e encaminhadas pelos profissionais, sem perder de vista o Projeto Ético-Político Profissional, no sentido de qualificar os diversos serviços em prol dos trabalhadores, principalmente a partir da melhoria das relações de trabalho que se dá, entre outras formas, pela atuação direta ou indireta na resolução de conflitos, na melhoria no fluxo de informação, no fortalecimento do protagonismo, corresponsabilidade e autonomia dos sujeitos no cotidiano do trabalho numa organização pública que se efetiva entre outras maneiras, pelo incentivo à educação permanente dos trabalhadores.

Outros desafios são somados, entre eles a construção da cultura interdisciplinar, capaz de facilitar os momentos de encontros para discutir os problemas em comum (inclui a presença efetiva nas reuniões do colegiado gestor da UGP), a necessidade de aumentar o número de profissionais qualificados na área de gestão de pessoas, principalmente no Núcleo de RH, para não haver sobrecarga de trabalho e garantir o alargamento de uma assessoria qualificada no HGT, bem como a melhoria do espaço físico da unidade, de modo que venha a facilitar o processo da escuta sigilosa e qualificada e o processo de planejamento da educação permanente.

Por fim, faz-se necessário reafirmar a importância de que desde a academia haja uma aproximação teórico/prática de estudantes não só com áreas tradicional- 
mente mais empregadoras do Serviço Social, mas também com a área de gestão de pessoas, visto que traz inúmeras questões que podem ser trabalhadas muito bem pelo Serviço Social, embora muitas delas não apenas por esta profissão.

\section{Recebido em 26/4/2011 - Aprovado em 13/6/2011}

\section{Referências bibliográficas}

ARAUJO, Maria Figuerêdo de. A construção/reconstrução das competências profissionais do assistente social diante da gestão do Serviço Social da Indústria (Sesi) a partir dos anos 90. Dissertação (Mestrado em Serviço Social) - Universidade Federal do Rio Grande do Norte, Natal, 2005.

BRASIL. Ministério da Saúde, Secretaria de Atenção à Saúde, Política Nacional de Humanização. HumanizaSUS: gestão participativa - cogestão. 2. ed. rev. Brasília: Editora do Ministério da Saúde, 2006.

. Ministério da Saúde, Secretaria de Atenção à Saúde, Núcleo Técnico da Política Nacional de Humanização. HumanizaSUS. Documento base para gestores e trabalhadores do SUS. 4. ed. Brasília: Editora do Ministério da Saúde, 2009.

BRAVO, M. I. S. Serviço Social e reforma sanitária: lutas sociais e práticas profissionais. São Paulo: Cortez/UFRJ, 1996.

CAMPOS, Gastão Wagner de Sousa. Reflexões sobre a construção do Sistema Único de Saúde (SUS): um modo singular de produzir política pública. Serviço Social \& Sociedade, São Paulo, n. 87, 2006.

CHIAVENATO, Idalberto. Introdução à moderna gestão de pessoas. In: . Gestão de pessoas: novo papel dos recursos humanos nas organizações. Rio de Janeiro: Campus. 1999.

CONSELHO FEDERAL DE SERVIÇO SOCIAL. Parâmetros para atuação de assistentes sociais na política de saúde. Brasília. 2010. (Série Trabalho e Projeto Profissional nas Políticas Sociais.)

CONSELHO REGIONAL DE SERVIÇO SOCIAL. Coletânea de leis. Natal: Cress, 2006.

FREIRE, M. B. O Serviço Social na reestruturação produtiva: espaços, programas e trabalho profissional. São Paulo: Cortez, 2003.

HARVEY, David. Do Fordismo à Acumulação Flexível. In: . Condição pós-moderna. 9. ed. Tradução de Adail U. Sobral e Maria S. Gonçalves. São Paulo: Loyola, 2000.

HOSPITAL GISELDA TRIGUEIRO. Plano de Ação do HGT (2010). Natal, 2010. 
IAMAMOTO, M. V. O Serviço Social na contemporaneidade: trabalho e formação profissional. 4. ed. São Paulo: Cortez. 2001.

; Projeto profissional, espaços ocupacionais e trabalho do assistente social na atualidade. In: COMISSÃO DE FISCALIZAÇÃO/CONSELHO FEDERAL DE SERVIÇO SOCIAL. Atribuições privativas do(a) assistente social em questão. Brasília, 2002.

MENICUCCI, Telma M. Gonçalves. Política de saúde no Brasil: entraves para universalização e igualdade da assistência no contexto de um sistema dual. Serviço Social \& Sociedade, São Paulo, n. 87, 2006.

PAIM, J. Reforma sanitária brasileira: contribuições para a compreensão e crítica. Salvador: EDUFBA; Rio de Janeiro: Fiocruz, 2008.

PIMENTA, Solange Maria. A estratégia da gestão na nova ordem das empresas. In:

Recursos humanos: uma dimensão estratégica. Belo Horizonte, UFMG, 1999.

RATES, Susana Maria. Unidades de produção como espaço de construção democrática. In: ARAÚJO, Gilvan F. de; RATES, Susana Maria (Orgs.). Cogestão e humanização na saúde pública: experiências construídas no Hospital Municipal Odilon Behrens. Belo Horizonte: Sigma Editora, 2008.

TEIXEIRA, S. F. Reflexões teóricas sobre democracia e reforma sanitária. In: (Org.).

Reforma sanitária em busca de uma teoria. São Paulo: Cortez, 1989. 